\title{
AVALIAÇÃO DO DANO PSÍQUICO ASSOCIADO AO DEPOIMENTO ESPECIAL
}

Danilo Salles Faizibaioff

Tribunal de Justiça do Estado de São Paulo (TJSP)

Instituto de Psicologia da Universidade de São Paulo (IPUSP)

Leila Salomão de La Plata Cury Tardivo

Instituto de Psicologia da Universidade de São Paulo (IPUSP)
Recebido em: 17/08/2020

$1^{\text {a }}$ revisão em: 05/06/2021

1ª revisão em: 20/06/2021

Aceito em: 28/06/2021

\section{RESUMO}

O Depoimento Especial de crianças e adolescentes vítimas de violência sexual vem sendo realizado por psicólogos judiciários. O objetivo deste artigo é discutir um modelo de avaliação psicológica prévia ao depoimento, voltada à ocorrência de danos psíquicos ou revitimização a ele associados. Para tanto, apresenta-se síntese reflexiva da experiência profissional dos autores em processos criminais envolvendo violência contra crianças e adolescentes, debatida à luz da literatura especializada nas áreas da Avaliação Psicológica e Psicologia Forense. Na dimensão intrapsíquica do dano, sugere-se a avaliação de fantasias, ansiedades e mecanismos de defesa da criança associados ao depor. Na dimensão intersubjetiva, aprecia-se seu nível de desenvolvimento cognitivo, raciocínio moral e vinculação ao entrevistador. Observou-se a aplicabilidade das técnicas projetivas temáticas - CAT-A, TAT e Procedimento de Desenhos-Estórias - para avaliar tais constructos, utilizando-se vinhetas clínico-forenses para ilustrar o raciocínio avaliativo. Conclui-se que proteger a criança do processo penal é proteger o próprio processo penal.

Palavras-chave: abuso da criança; psicologia forense; testes de personalidade. 


\section{PSYCHOLOGICAL DAMAGE ASSOCIATED WITH SPECIAL INQUIRY ASSESSMENT}

\section{ABSTRACT}

The Special Inquiry of child and adolescent sexually assaulted has been discharged by forensic psychologists. This article aims to discuss a model of psychological assessment prior to the inquiry, targeted to the occurrence of psychological damage or revictimization associated with it. For this, a reflexive synthesis of the authors' professional experience in criminal proceedings involving violence against children is presented, discussed within the specialized literature in Psychological Assessment and Forensic Psychology In the damage's intrapsychic dimension, it is suggested to assess child's fantasies, anxieties and defense mechanisms regarding testifying. In the intersubjective dimension, their level of cognitive development, moral reasoning and attachment to the interviewer is evaluated. The applicability of thematic projective techniques - CAT-A, TAT and Drawing-Stories Procedure was observed to approach such constructs, using clinical-forensic vignettes to illustrate the evaluative reasoning. It is concluded that protecting the child from the criminal suit is protecting the criminal suit itself.

Keywords: child abuse, forensic psychology; personality tests. 


\section{EVALUACIÓN DEL DAÑo PSíquICO RELACIONADO CON EL TESTIMONIO ESPECIAL}

\section{RESUMEN}

El Testimonio Especial de niños y adolescentes víctimas de violencia sexual ha sido realizado por psicólogos judiciales. El objetivo de este artículo es discutir un modelo de evaluación psicológica previa a la inquisición, dirigido a la ocurrencia de daños psicológicos o revictimización correlativos. Para eso, se presenta una síntesis reflexiva de la experiencia profesional de los autores en procesos penales de violencia infanto-juvenil, debatida con la literatura especializada en las áreas de Evaluación Psicológica y Psicología Forense. En la dimensión intrapsíquica del daño, evaluanse fantasías, ansiedades y mecanismos de defensa del niño. En la dimensión intersubjetiva, apreciase su nivel de desarrollo cognitivo, razonamiento moral y vinculación al entrevistador. Se observó la aplicabilidad de las técnicas proyectivas temáticas - CAT-A, TAT y Procedimiento de Dibujo-Cuentos - en la evaluación, usándose viñetas clínico-forenses para ilustrar el razonamiento evaluativo. Se concluye que proteger al niño del proceso penal es proteger el proprio proceso penal.

Palabras clave: abuso de niños; psicología forense; pruebas de personalidad. 


\section{INTRODUÇÃO}

A Lei $n^{\circ}$ 13.431/2017 (Presidência da República, 2017), regulamentada pelo Decreto no 9.603/2018 (Presidência da República, 2018), estabelece o sistema de garantia de direitos da criança e do adolescente vítima ou testemunha de violência, formalizando sua participação em processos judiciais cuja matéria lhes afete, conforme já preconizara o Estatuto da Criança e do Adolescente (Presidência da República, 1990a). Sua vigência tem levado à crescente designação de psicólogos judiciários para realizar o procedimento do Depoimento Especial (DE) (Mello \& Faizibaioff, 2021; Rovinski \& Pelisoli, 2019), uma forma diferenciada de participação das vítimas infanto-juvenis em audiências criminais que visam à responsabilização penal do suposto perpetrador da violência (Santos \& Coimbra, 2017). Em vez de deporem diretamente ao magistrado, na presença do promotor e do defensor do acusado, elas passaram a gozar do direito de prestar seu testemunho em uma sala reservada, apenas na presença do psicólogo, sendo a inquirição - tecnicamente conhecida como entrevista forense - gravada e transmitida em tempo real à sala de audiência (Mello \& Faizibaioff, 2021).

Embora haja consenso entre os autores quanto às melhores práticas para conduzir a entrevista forense em si (Benia, 2015), persiste uma lacuna no trabalho avaliativo que cabe aos psicólogos empreenderem antes do DE. Trata-se da "avaliação da existência de condições da criança para enfrentar essa experiência" (Santos \& Coimbra, 2017, p. 605), isto é, de suas "capacidades cognitivas e emocionais para o relato de vivências traumáticas" (Rovinski \& Pelisoli, 2019, p. 141). Em posse dos resultados dessa avaliação, o profissional indica ou contraindica, ao magistrado, a participação da criança ou adolescente no $D E$, visando à preservação da integridade psicológica e à não-revitimização desses sujeitos (Mello \& Faizibaioff, 2021).

Originalmente chamado de Depoimento sem Dano (Coimbra, 2014), pouco ainda se discutiu sobre o que, em termos psicológicos, seria o tal dano psíquico, ou mesmo a tão citada vitimização secundária ou revitimização associada ao DE (Subijana \& Echeburúa, 2018). Ao contrário da descrição sobre os diferentes tipos de violência (Presidência da República, 2017), a revitimização foi tratada de forma genérica pelo legislador: "discurso ou prática institucional que submeta crianças e adolescentes a procedimentos desnecessários, repetitivos, invasivos, que levem as vítimas ou testemunhas a reviver a situação de violência ou outras situações que gerem sofrimento, estigmatização ou exposição de sua imagem" (Presidência da República, 2018, p. 2).

Entretanto, o texto legal é inespecífico sobre quais seriam os "procedimentos desnecessários, repetitivos, invasivos" e as "situações" geradoras de "sofrimento, estigmatização ou exposição" da criança e do adolescente. Sem profunda compreensão teórica a respeito do tão citado dano psíquico, não surpreende a ausência de diretrizes metodológicas para avaliar o risco de sua ocorrência, a qual se busca predizer por meio da avaliação psicológica (Mello \& Faizibaioff, 2021). 
Este artigo nasce do encontro entre tal lacuna com a experiência prática de ambos os autores, após anos de atuação profissional em vara criminal especificamente voltada para julgar crimes de violência sexual contra crianças e adolescentes.

\section{DIMENSÕES DO DANO PSÍqUICO ASSOCIADO AO DE}

Visando ao aprofundamento teórico do dano psíquico associado ao $D E$, partimos dos aportes do campo de estudos sobre Trauma e Testemunho à Psicologia Clinica e Jurídica (Seligmann-Silva, 2008). Seu objeto é a dimensão social e coletiva da memória e do testemunho de vítimas de genocídios, perseguições étnicas e outras formas de violência estatal, tal qual o nazifascismo alemão. Diante da "falta de representação para o horror vivido" (Coimbra, 2014, p. 371), os sobreviventes dessas chacinas podem não lograr a tarefa de testemunhar a violência sofrida de forma racionalmente verossímil ou verbalmente articulada (Osmo \& Kupermann, 2017), descarrilando-se da lógica do discurso jurídico (Seligmann-Silva, 2008). Daí o sério temor de descrédito e desqualificação ao tentarem contar a outrem, em palavras, as violações e torturas sofridas, tal como se observou no famigerado sonho do escritor italiano Primo Levi: "o Levi que sonha com seu público ouvinte que o abandona já previa a sensação de inverossimilhança gerada pelos fatos que narraria e a consequente acusação de mentiroso que o esperava" (p. 70).

Além do risco de desautorização traumática por terceiros, a mera tentativa de falar sobre o horror vivido já ameaça a dinâmica psíquica dos sobreviventes, omo Rosenblum (2002) aponta ao debruçar-se sobre o mesmo problema pela ótica da Psicanálise. Analisando o suicídio de Primo Levi, ela assinala o turbulento impacto de fantasias inconscientes e afetos desorganizadores eliciados por sua tentativa de relatar as violências sofridas no campo de concentração. Em sua interpretação, quando da rememoração e narração desses episódios traumáticos, a intensidade da atividade ansiogênica correlata derrubou as defesas inconscientes do depoente, deixando seu psiquismo à deriva (Rosenblum, 2002). "Pode-se morrer de dizer?" questiona-se a psicanalista (p. 147). Anne Alvarez, psicanalista canadense cuja experiência com crianças violentadas já ressaltara o perigo do estímulo à rememoração traumática precipitada e inadvertidamente no setting clínico, aproxima esse achado ao nosso objeto de estudo - o dano psíquico associado ao DE. Ela observou que

enquanto o paciente mais moderadamente traumatizado, cujo distúrbio está afetando sua personalidade no nível neurótico, pode precisar lembrar o trauma para poder esquecer, as crianças mais danificadas, cujo trauma é mais severo e crônico, podem precisar esquecer o trauma para poderem ser capazes de lembrar. (Alvarez, 1994, p. 161)

Ainda que não se trate de igualar a experiência testemunhal de sobreviventes de massacres e genocídios àquela das crianças vítimas de violência sexual, acreditamos que se possam aproximar ambas as situações visando conferir um estatuto metapsicológico à noção de dano psíquico associado ao $D E$, o que 
permitirá discutir um modelo avaliativo voltado ao risco de sua ocorrência. Em relação ao campo do Trauma e Testemunho, concordamos com Coimbra (2014): "não seria possível a apropriação da multiplicidade de estudos desse campo para a análise do tema que abordamos aqui? Ali, estão em jogo a sobrevivência a uma situação-limite e a expressão da memória com base em uma narrativa" (p. 371). Considerando, ademais, o potencial psiquicamente mortífero que a Psicanálise contemporânea vincula à rememoração e verbalização de episódios excepcionalmente traumáticos (Rosenblum, 2002), aí incluídos certos casos de violência sexual infanto-juvenil (Alvarez, 1994), faz-se o alerta: se o falar tudo (repport everything) nem sempre leva ao melhor mesmo em um tratamento psicanalítico (Ogden, 2013), tampouco inexistem perigos na inquirição forense, ainda que especial.

Pois, subjacente a qualquer objetivo conscientemente perseguido (como verbalizar memórias episódicas atinentes a uma violência sofrida/testemunhada), subsiste, na dimensão intrapsíquica, uma turbulenta tarefa inconsciente: o enfrentamento de intensas ansiedades persecutórias e depressivas, cuja atuação cria um obstáculo psicológico à concretização do objetivo racionalmente proposto (Castanho, 2007). Já no plano intersubjetivo, a forma como os adultos recebem a revelação da criança sobre uma violência sofrida é determinante para a elaboração da experiência ou o agravamento do trauma (Osmo \& Kupermann, 2017). Caso a criança seja desacreditada ou desautorizada quando arrisca falar sobre o episódio abusivo a uma terceira pessoa, supostamente digna de sua confiança (Thouvenin, 1997), institui-se um "trauma suplementar" (p. 93), podendo-Ihe ser ainda mais danoso do que os atos abusivos em si (Rovinski \& Pelisoli, 2019).

Assim como na primeira revelação sobre uma violência sofrida, uma vez nos meandros do processo penal a criança também se arrisca no endereçamento de seu testemunho. Juízes, promotores, advogados, assistentes sociais e psicólogos, a despeito de seu papel técnico, não estão imunes à influência de representações sociais sobre infância e sexualidade que podem, em algum nível, levar à má interpretação sobre a credibilidade da palavra da criança (Eloy, 2012; Rovisnki \& Pelisoli, 2019). O risco do desmentido aumenta ainda mais se considerarmos que, no Brasil, ainda se assiste a baixas taxas de resolução de crimes, estejam ou não ligados ao tipo penal do estupro de vulnerável (Coimbra, 2014). Embora não seja do escopo deste artigo analisar essa limitação do Poder Judiciário brasileiro, cabe assinalá-la visando ao seu contínuo aperfeiçoamento e à cautela que devem seus atores adotar para não facilitar a ocorrência de danos psíquicos às vítimas, a qual também tem sido compreendida como violência institucional (Presidência da República, 2018, 2017).

Em síntese, partindo dos estudos sobre Trauma e Testemunho e adotando o arcabouço conceitual da Psicanálise contemporânea, propomos conceber o dano psíquico associado ao DE em duas dimensões: intrapsíquica e intersubjetiva. $\mathrm{Na}$ primeira, o dano corresponde à atuação excessiva de ansiedades depressivas e persecutórias, ligadas a fantasias mais ou menos conscientes (Cintra \& Figueiredo, 
2010) e cuja intensidade os mecanismos de defesa da criança-depoente não conseguem atenuar no momento da inquirição (Piccolo, 2017). Na segunda, o dano é o próprio desmentido, isto é, o questionamento da credibilidade da palavra da criança por parte dos adultos a quem ela endereça seu testemunho (Osmo \& Kupermann, 2017), incluindo os próprios atores do Poder Judiciário (Eloy, 2012).

\section{OBJETIVO}

Uma vez conceituado o dano psíquico em suas dimensões intra e intersubjetiva, pretende-se discorrer sobre os constructos psicológicos envolvidos na avaliação prévia ao $D E$, explorando técnicas pertinentes para predizer a ocorrência de possíveis danos quando da execução do procedimento. Trata-se, assim, de apresentar um modelo de avaliação psicológica voltado para a detecção de potenciais danos psíquicos associados à entrevista forense sobre uma suposta violência sofrida por crianças e adolescentes.

$\mathrm{Na}$ dimensão intrapsíquica do dano, os constructos a serem apreciados na avaliação serão os perigos fantasiados, as ansiedades deles decorrentes e os mecanismos de defesa empregados pela criança para equalizar o nível de tensão ansiogênica. Já no âmbito intersubjetivo, dada a possibilidade de desautorização da palavra do depoente pelo próprio Judiciário, cabe apreciar aspectos de seu desenvolvimento cognitivo, nível de raciocínio-moral e a qualidade da vinculação ao entrevistador de referência (psicólogo judiciário), o que permitirá Ihe explicar a demanda judicial para ouvi-la em juízo, colher sua opinião a respeito de sua participação e produzir uma prova testemunhal de qualidade, com menos chances de ter sua confiabilidade questionada pelos juristas.

\section{MÉTODO}

Este estudo, de natureza qualitativa, estruturou-se por meio de síntese reflexiva da experiência profissional dos autores, teoricamente debatida à luz da literatura especializada nas áreas da Psicologia Forense e Avaliação Psicológica. Trata-se de um psicólogo judiciário, atuante como perito de confiança na primeira vara criminal especializada no julgamento de denúncias de violência infanto-juvenil do TJSP (Mello \& Faizibaioff, 2021), e uma psicóloga clínica com larga experiência em assistência técnica, docência e pesquisa envolvendo a mesma matéria (Tardivo, 2016).

Metodologicamente, o presente artigo é amparado pela Resolução $n^{\circ}$ 510/2016 do Conselho Nacional de Saúde, a qual, em seu Art. $1^{\circ}$ (Parágrafo Único, VII), define a "pesquisa que objetiva o aprofundamento teórico de situações que emergem espontânea e contingencialmente na prática profissional" (Conselho Nacional de Saúde, 2016, p. 2). Houve utilização de vinhetas clinico-forenses baseadas em dados reais para ilustrar o raciocínio avaliativo proposto, o qual possui, a nosso ver, importante aplicação prática. Afinal, por se tratar de um campo de atuação 
profissional recente para os psicólogos atuantes no Poder Judiciário - o decreto que regulamentou a lei do DE data de dezembro de 2018 -, ainda se observa insegurança desses profissionais quando designados pelos magistrados para indicar ou contraindicar a participação de crianças e adolescentes em audiências criminais.

Partiu-se da já assinalada relevância das técnicas projetivas de natureza temática na avaliação do estado mental de crianças e adolescentes sexualmente violentados (Tardivo, 2016; Torres, 2014), como o CAT-A (Miguel, Tardivo, Silva, \& Tosi, 2010), o TAT (Brelet-Foulard \& Chabert, 2008; Murray, 2005) e o Procedimento de Desenhos-Estórias (D-E) (Tardivo, 2020; Trinca, 2020). Tecnicamente, a aplicação desses instrumentos deve estar associada a, pelo menos, uma entrevista psicológica (Bleger, 2015) com a criança e seu(s) responsável(eis) (Pinto, 2014), ou mesmo ao ludodiagnóstico no contexto jurídico (Anaf, Menichetti, \& Evangelista, 2012).

O uso de técnicas projetivas agiliza o processo avaliativo, pois elas captam informação sobre diferentes níveis de funcionamento mental em curto intervalo de tempo (Grassano, 2012). Assim, otimiza-se o pouco tempo do qual o psicólogo judiciário dispõe para essas avaliações (Shine \& Lourenço, 2018), facilitando a expressão de aspectos inconscientes dos infantes cujo acesso, restrito unicamente à linguagem verbal, encontraria sérias resistências (Tardivo, 2020, 2016). Ademais, considerando a situação de depor em juízo como experiência inédita e estressante para crianças e adolescentes (Rovinski \& Pelisoli, 2019), tem-se que os instrumentos projetivos "avaliam o modo de pensar, sentir e agir do cliente em situações mais complexas, pouco familiares, menos estruturadas e interpessoalmente mais estressantes" (Villemor-Amaral \& Resende, 2018, p. 127).

$\mathrm{Na}$ avaliação psicológica prévia ao $\mathrm{DE}$, destacam-se especialmente as técnicas projetivas temáticas, por meio das quais o sujeito é convidado a imaginar e verbalizar histórias a partir de estímulos visuais mais ou menos saturados (Pinto, 2014). Sua aplicação permite a apreciação de constructos psicológicos importantes para a predição de danos associados ao $\mathrm{DE}$, pois, "através da elaboração de temas e contos, a pessoa revela seus conflitos e desejos fundamentais, suas expectativas, modelos de reação, mecanismos de defesa e os principais momentos de sua trajetória de vida" (p. 146). Adotando-se o referencial psicanalítico para a interpretação dos dados (Miguel et al., 2010; Pinto, 2014; Tardivo, 2020; Trinca, 2020), transcende-se a mera apreciação da dimensão consciente do funcionamento psíquico do avaliando, aportando maior segurança à delicada tarefa de indicar ou contraindicar sua participação em audiência penal.

Já no aspecto formal, a prova projetiva temática implica uma tarefa similar ao próprio DE: verbalizar uma história, com começo, meio e fim, integrando-se detalhes objetivos que se apresentam à percepção em um enredo coerente (BreletFoulard \& Chabert, 2008; Miguel et al., 2010), ao mesmo tempo em que se lida, 
inconscientemente, com cargas significativas de ansiedades depressivas e persecutórias (Castanho, 2007).

\section{RESULTADOS E DISCUSSÃO}

\section{PERIGOS FANTASIADOS, ANSIEDADES E MECANISMOS DE DEFESA}

Dada a concepção psicanalítica de um psiquismo em constante conflito (Pinto, 2014), "as ansiedades referem-se ao que está por trás dos conflitos, àquilo que de que realmente a criança se defende, o motivo fundamental da configuração dos conflitos" (Miguel et al., 2010, p. 83). A atividade ansiogênica decorre da atuação de fantasias inconscientes, isto é, os representantes psíquicos da atividade pulsional segundo a psicanálise kleiniana (Cintra \& Figueiredo, 2010). Na dimensão intrapsíquica da experiência humana, o que verdadeiramente nos angustia e ameaça, em última instância, é o conteúdo irracional e conflituoso das fantasias, ou seja, os "perigos fantasiados" (Piccolo, 2017, p. 256). Por exemplo,

diante de uma pessoa que manipula seus vínculos com condutas que relacionamos com mecanismos de isolamento intensos (sem afeto, carente de emoções, fechada em si mesma, etc.), perguntamo-nos por que necessita fazê-lo. Sua fantasia será: "se não me distancio, sou invadido por tanto afeto que enlouqueço", "sinto o que acontece com o objeto como acontecendo a mim e enlouqueço", "tanta agressão pode irromper em mim que, se não me fecho em mim mesmo, posso explodir e fazer explodir". (Piccolo, 2017, pp. 259-60)

Do ponto de vista econômico, a atuação de ansiedades (depressivas e persecutórias) gera tensão intrapsíquica, energia motriz para o funcionamento do aparelho mental (Cintra \& Figueiredo, 2010). Caso excessiva, contudo, a atividade ansiogênica perturba o bom funcionamento do psiquismo, dificultando ao sujeito realizar as tarefas objetivas às quais se propõe (Castanho, 2007) - tal como depor em juízo sobre uma violência sofrida. Na experiência dos autores, veem-se muitas crianças e adolescentes chegarem com grande carga ansiogênica à avaliação psicológica no fórum criminal. Geralmente, seus pais já foram previamente informados, por telefone ou intimação, da demanda judicial para que seus filhos participem de futura audiência penal em desfavor do seu algoz, avisando-lhes em seguida (Mello \& Faizibaioff, 2021).

Quanto à ansiedade persecutória, ela tende a aparecer, às vítimas, como medo de retaliação do réu, o qual frequentemente proferiu ameaças à criança ou à sua família caso ela viesse a revelar o episódio abusivo (Intebi, 2008). Tais perigos fantasiados, com os quais os depoentes hão de se haver, manifestam-se ainda de inúmeras outras formas: um estudo com quase duzentas crianças e adolescentes vitimados apontou, como manifestações comuns de temores persecutórios 
associados à verbalização da violência sexual sofrida, o receio desses sujeitos em envolver-se com serviços de proteção e com próprio Judiciário, a preocupação com seu futuro após depor em juízo, o medo de serem desalojadas de suas casas e o temor de que seus pais fiquem preocupados, enlouquecidos ou mesmo que façam algo ruim a eles ou a si mesmos (Schaeffer, Leventhal, \& Asnes, 2011).

Quanto à ansiedade depressiva, observa-se o medo das crianças e adolescentes em perderem seus amigos e o amor dos pais, aos quais, no mínimo, temem causar sentimentos de chateação ou tristeza com seu depoimento (Schaeffer et al., 2011). Observa-se esse ponto quando os genitores assistem ao testemunho da prole: muitas vezes, eles só escutam o relato da violência com riqueza de detalhes por meio do $\mathrm{DE}$, ante o qual reagem com extremo desconforto. Ademais, como a ambivalência perante a figura do réu é comum em situações de violência sexual (Intebi, 2008; Volbert \& Steller, 2014), as crianças também hão de se haver com ansiedades depressivas associadas ao receio de que seu depoimento traga problemas ao seu algoz, manifestando-se como vivências de preocupação com um objeto simultaneamente temido, odiado e amado, o qual poderá ser agredido ou mesmo morto caso condenado (Schaeffer et al., 2011).

Para equalizar o nível de tensão das ansiedades e preservar o equilíbrio do aparelho mental, entram em ação os mecanismos de defesa, isto é, dispositivos intrapsíquicos que reduzem a intensidade ansiogênica atrelada aos perigos fantasiados, tal como o mecanismo de isolamento citado acima no exemplo de Piccolo (2017). Os mecanismos de defesa possuem diferentes graus de sofisticação e eficácia (Miguel et al., 2010; Tardivo, 2020): em um extremo, mecanismos primitivos, como a clivagem e a identificação projetiva excessiva, promovem alívio radical e imediato da ansiedade, mas às custas da evacuação de aspectos do próprio Self, cuja impossibilidade de integração paralisa ou deteriora o desenvolvimento psíquico (Grassano, 2012; Salvitti, 2011). Já mecanismos mais sofisticados, baseados no recalcamento e na sublimação (Miguel et al., 2010; Piccolo, 2017), equalizam os níveis de ansiedade sem resultar na evacuação psicótica ou na negação maníaca desses mesmos aspectos, possibilitando sua conscientização e integração à personalidade (Cintra \& Figueiredo, 2010).

Investigar, previamente, os mecanismos de defesa e contra quais perigos fantasiados eles atuariam durante um eventual DE é importante na medida em que seu desconhecimento e a impossibilidade de enfrentamento das ansiedades correlatas constituem-se como importantes barreiras para a vítima depor em juízo (Azzopardi, Eirich, Rash, MacDonald, \& Madigan, 2019). Na avaliação psicológica, pode-se guiar a apreciação desses constructos analisando a produção projetiva da criança pelos seguintes pontos do referencial de Tardivo (2020):

5. De que modo se poderiam descrever os impulsos da pessoa? Observa-se a prevalência de impulsos amorosos ou destrutivos? 6. Em relação às ansiedades e angústias (paranoides e depressivas), qual é sua natureza? 7. Considerando-se os 
mecanismos de defesa descritos pela psicanálise, quais deles se manifestam predominantemente? (p. 69)

A prevalência de impulsos destrutivos sobre os amorosos sugere déficits nas defesas reparatórias do sujeito (Piccolo, 2017), deixando seu psiquismo à mercê de excessos ansiogênicos potencialmente danosos (Grassano, 2012), já que, "quando a ansiedade é intolerável, há inibição e empobrecimento generalizado da vida mental" (Salvitti, 2011, p. 130). Assim, ante uma avassaladora atividade ansiogênica que toma o ego de assalto, a criança tende a apelar para defesas primitivas, as quais Ihe promovem um rápido alívio ansiolítico às custas da negação maníaca ou mesmo da excisão esquizoide de aspectos fundamentais de si mesmo (Cintra \& Figueiredo, 2010).

Pode-se notar tal aspecto ao longo da produção temática do avaliando, como em um exemplo de aplicação do Procedimento de Desenhos-Estória em uma criança de dez anos, vítima de múltiplas violências: "conforme a produção de Murilo vai avançando, nota-se aumento das vivências agressivas e destrutivas, associadas com progressivos sinais de desorganização. Vemos, cada vez mais, passagens ao ato por parte das personagens principais, com agressões verbais e físicas entre elas" (Faizibaioff \& Bandeira, 2017, p. 1097). Trata-se, aqui, de um indicativo de dano intrapsíquico que iria na direção da contraindicação da participação dessa criança em um eventual DE.

Analisar as problemáticas e afetos delas decorrentes nas histórias construídas pela criança possibilita avaliar a natureza e intensidade das ansiedades enfrentadas ante uma situação nova e estressante, assim como a presença e adequação das soluções empregadas pelos personagens principais (heróis) para solucionar os conflitos apontam para a sofisticação e eficácia de seus mecanismos de defesa intrapsíquicos (Miguel et al., 2010). Quando se observa "expressão de conteúdos primitivos e intensos, com perdas de qualidade do discurso (falhas de lógica e articulação)", ou mesmo se "o discurso permanece relativamente organizado, mas não há possibilidade de enfrentamento ou solução do conflito subjacente" (p. 85), sugere-se intensa atividade ansiogênica e baixa capacidade defensiva contra elas em uma situação tensa e desconhecida. Caso se proceda com o DE de uma criança em tais condições, situação similar pode emergir em seu mundo interno, expondoa a danos mais ou menos significativos.

$\mathrm{Na}$ experiência avaliativa dos autores, uma adolescente, supostamente violentada pelo genitor, vinha construindo as histórias do TAT com razoável adequação formal. Contudo, quando da apresentação da prancha $13 \mathrm{HF}$, a avalianda teve uma reação disruptiva, arremessando o cartão para longe e gritando um sonoro "NÃO!" (sic). Como a solicitação latente dessa prancha é a "fantasmática incestuosa mortífera" do contexto edipiano - cuja alta carga ansiogênica "pode desencadear um transbordamento e uma desorganização patentes" do psiquismo (BreletFoulard \& Chabert, 2008, p. 71) -, o psicólogo encerrou imediatamente a aplicação, realizando intervenções de continência e concluindo pela contraindicação de sua participação no DE. Afinal, se já no contexto simbólico da aplicação do instrumento 
a alta carga ansiogênica associada a fantasias incestuosas pareceu extravasar sua capacidade defensiva - impedindo-a de imaginar e verbalizar uma história desse teor -, a que custo intrapsíquico ela lograria evocar e verbalizar detalhes da suposta violência intrafamiliar sofrida no dia da audiência?

Pois são diferentes, como aponta Green (2008), o retorno do reprimido e o "retorno do cindido" (p. 112). No primeiro caso, quando se pressupõe a atuação da repressão, um mecanismo de defesa sofisticado (Tardivo, 2020), a rememoração de um evento traumático encerra algum sofrimento momentâneo ao sujeito, mas sua capacidade de atenuar o excesso ansiogênico dele decorrente protege-o do dano. Aí, espera-se posterior recuperação do depoente, como uma espécie de pósoperatório bem-sucedido. Contudo, ao se estimular a evocação mnemônica de episódios de violência em um aparelho psíquico marcado pela forte atuação de "mecanismos fóbicos, imaturos ou desorganizados" (Miguel et al., 2010, p. 85), como na vinheta apresentada acima, é a própria paralisia ou deterioração de um psiquismo já indefeso que se apresenta como consequência. Neste caso, o retorno do cindido encerra ataques às próprias funções mentais do sujeito, como a percepção, memória, juízo de realidade e diferenciação entre o mundo interno e externo (Grassano, 2012; Salvitti, 2011), revelando que "o dano psíquico distinguese do sofrimento por inserir em seu conceito a noção de lesão às faculdades mentais" (Rovinski, 2008, p. 179).

O ponto fundamental para analisar o arsenal defensivo das crianças e adolescentes são os desfechos construídos paras as histórias, sendo que "uma boa integração do ego é indicada por desfechos realistas que apresentam soluções adequadas. Desenlaces negativos, omitidos ou irrealistas indicam baixa integração do ego" (Miguel et al., 2010, p. 86). Por exemplo, na prancha 7 do CAT-A, um indício positivo se apresenta se o macaco (enquanto herói) consegue escapar do tigre utilizando os recursos ambientais disponíveis (cipós, árvores). Contudo, quando ele é devorado pelo tigre, ou mesmo quando presa e predador viram amigos, sugerese, respectivamente, possibilidade de falha de seus mecanismos de defesa ante altas cargas de ansiedade persecutória e negação maníaca da destrutividade interna ou externa. Tal dinâmica poderia, em uma situação de depoimento sobre uma violência sofrida, deixar a criança à mercê de um incremento significativo da atividade ansiogênica, expondo-a ao dano em sua dimensão intrapsíquica.

Para ilustrar esse ponto, cita-se mais uma vinheta da experiência avaliativa dos autores. Trata-se de uma criança de nove anos, em cujas histórias do CAT-A todos os heróis morriam, não sem antes enfrentarem graves privações às suas necessidades fundamentais (Tardivo, 2020), sucumbindo a vivências de fome, abandono e despedaçamento. A denúncia era de abuso sexual, físico e negligência grave por parte de seus genitores, e a figura materna lhe aparecia, na prova temática, de forma significativamente ambivalente: incapaz de satisfazer suas necessidades fundamentais, mas, ainda assim, investida de amor e anseio de cuidados no psiquismo da criança. Neste caso, optou-se pela contraindicação de sua participação no $\mathrm{DE}$, pois suas defesas não pareceram dar conta, naquele 
momento, de equalizar a alta carga de ansiedade depressiva esperada caso ele viesse a depor contra uma figura amada e da qual ainda sentia necessitar, apesar das supostas violências por ela perpetradas.

Também é digna de preocupação uma produção projetiva onde não se observa o desenvolvimento de verdadeiras histórias, isto é, a emergência de uma problemática que enseje a busca por soluções e satisfação das necessidades das personagens (Brelet-Foulard \& Chabert, 2008; Miguel et al., 2010; Murray, 2005). A mera descrição objetiva das pranchas, ou mesmo um relato afetivamente anestesiado, sugerem que a intensidade das ansiedades atreladas à tarefa objetiva das provas temáticas não é suportável para a criança naquele momento, quando ela privilegia estratégias mentais pouco sofisticadas que impedem o contato com o conflito intrapsíquico. Isso sugere risco de dano caso a criança venha a depor em juízo: embora ela possa descrever uma grave violência vivida de forma aparentemente desafetada, não o faz sem lançar mão de mecanismos primitivos, de natureza fundamentalmente dissociativa (Intebi, 2008).

Já a presença da sublimação, o mais sofisticado dos mecanismos de defesa (Tardivo, 2020), é um sinal favorável à participação da criança no DE. Na teoria kleiniana, a sublimação corresponde aos ganhos da posição depressiva (Piccolo, 2017), estando estritamente associada à capacidade de reparação: enquanto as defesas obsessivas buscam controlar a agressividade dirigida contra o objeto amado, aqui a preocupação é em consertá-lo, integrá-lo, juntá-lo e recriá-lo, já que há tolerância egóica suficiente para aceitar e integrar a própria destrutividade, isto é, suportar altas cargas de ansiedade depressiva (Cintra \& Figueiredo, 2010). Quanto ao setting avaliativo, tem-se que

a reparação é um mecanismo de defesa que Melanie Klein havia observado, nas sessões de análise, sempre que as crianças sentiam culpa pelos ataques imaginários a seus objetos de amor e desejavam devolver a eles sua integridade ferida. Nesses momentos, é muito frequente que as crianças façam desenhos, queiram colar e consertar os brinquedos quebrados e expressem com toda clareza a aspiração ao bem estar e à saúde das pessoas que amam. (Cintra \& Figueiredo, 2010, p. 81)

A própria entrega à tarefa projetiva já é, em si, uma forma de recriação sublimatória, quando se observa, na atitude geral do examinando, clima de introspeção emocional e empenho para realizar a prova da melhor forma possível, sem meticulosidade exagerada (Piccolo, 2017). Trata-se de reconhecer o outro "como um objeto total, valioso e necessitado, mas autônomo, e na manutenção de uma relação de amor, mesmo em experiências de frustração e perda" (Grassano, 2012, p. 52).

Nota-se, em contraste à sofisticação do mecanismo de reparação, a estratégia de manejo ansiolítico operado pelas defesas maníacas perante o temor inconsciente de atacar/estragar um objeto amado: para solapar vivências dolorosas de natureza 
depressiva, elas estimulam a negação da própria destrutividade do sujeito e, no limite, tendem ao desprezo, controle e triunfo sobre o objeto (Piccolo, 2017). O uso excessivo de defesas maníacas indica que o avaliando, naquele momento, não pode processar a ansiedade depressiva de forma mais aprimorada - isto é, pela sublimação (Cintra \& Figueiredo, 2010) -, revelando baixa sofisticação de seu arsenal defensivo. Caso venha a depor, então, existe risco de danos intrapsíquicos.

Na experiência avaliativa dos autores com o Procedimento de Desenhos-Estórias, uma criança desenhou duas entidades humanoides viradas uma de frente para a outra, colorindo a primeira com tons dourados e, a segunda, de cinza. Posteriormente, construiu uma estória na qual identificou a primeira como a felicidade e, a segunda, como a tristeza, assinalando a impossibilidade de uma existir sem a outra e, logo, a importância de ambas para a vida das pessoas. Tratouse de um indício interpretado como expressão da solidez de sua capacidade reparatória, na medida em que sugeria a possibilidade de a criança tolerar vivências ambivalentes e dolorosas, comunicando aspectos profundos de si mesmo. Dada a sofisticação de seu repertório defensivo, o parecer técnico quanto à sua participação no DE foi favorável.

\section{ASPECTOS COGNITIVOS}

Seja (1) pela influência de representações sociais segundo as quais a criança é naturalmente sugestionável e habita um mundo fantasioso (Eloy, 2012), (2) graças à ampla defesa do réu no processo penal (Subijana \& Echeburúa, 2018), (3) em face da constatação de que até $5 \%$ das denúncias de abuso sexual infantil são falsas (O'Donohue, Cummings, \& Willis, 2018) ou (4) pelos obstáculos à produção de um testemunho logicamente verossímil quando do relato de episódios extraordinariamente traumáticos (Seligmann-Silva, 2008), não é incomum que os juristas (magistrados, promotores e advogados) questionem a credibilidade do depoimento das crianças e adolescentes após sua coleta pelo método do DE.

Embora as vítimas possam suportar o estresse da inquirição em si utilizando sofisticados mecanismos de defesa, o questionamento da veracidade de sua palavra pode se lhes apresentar como uma desautorização traumática (Osmo \& Kupermann, 2017), causando-lhes danos psíquicos, desta vez, pela via intersubjetiva. Não é de se estranhar, então, que uma das principais barreiras à revelação do ato abusivo por parte das crianças e adolescentes seja, justamente, o medo de serem desacreditadas e taxadas como mentirosas pelos mesmos adultos aos quais se arriscam a contar o ocorrido (Schaeffer et al., 2011).

Por isso, cabe também avaliar a capacidade desses sujeitos de fornecer um testemunho confiável do ponto de vista forense, isto é, a reunião de certas habilidades cognitivas que permitem ao depoente codificar, armazenar e evocar verbalmente memórias episódicas de longo prazo referentes a uma suposta violência sofrida (Köhnken, Manzanero, \& Scott, 2015). A maioria das crianças préescolares, sobretudo menores de 5 anos, ainda não desenvolveu plenamente essas competências (Muñoz et al., 2016), diminuindo a chance de verem seu testemunho 
investido de credibilidade no setting forense (Melkman, Hershkowitz, \& Zur, 2017). Ainda assim, dada a grande diferença de acesso a oportunidades sociais para estimular o desenvolvimento cognitivo nas famílias brasileiras, deve-se proceder à apreciação do caso-a-caso (Rovinski \& Pelisoli, 2019).

Uma importante habilidade cognitiva é o monitoramento da fonte (Benia, 2015), isto é, a capacidade de discriminar de onde vem a informação rememorada e verbalizada no DE: da própria experiência vivida, de um sonho ou devaneio, de alterações psicopatológicas, de relato induzido por terceiros etc. (Volbert \& Steller, 2014). O pleno desenvolvimento desta capacidade também não é esperado em crianças pré-escolares, sendo que, quanto maior o intervalo de tempo entre a primeira revelação da violência e a designação da audiência penal, maiores as possibilidades de contaminação mnemônica (Izquierdo, 2018) e incapacidade de fornecer um testemunho confiável (Köhnken et al., 2015). Ademais, crianças com cerca de três anos de idade tendem a não reter informações na memória de longo prazo episódica por mais de três semanas, sendo que, apenas por volta dos seis anos, a capacidade de armazenamento estaria melhor desenvolvida (Rovinski \& Pelisoli, 2019).

Como se considera praticamente impossível evocar, pela via da linguagem, memórias de eventos ocorridos antes dos três anos de idade (Izquierdo, 2018), também é importante atentar, na avaliação, a quando os supostos fatos teriam ocorrido, independente da idade atual da criança ou do adolescente. Nesse sentido, observou-se que (1) revelações prévias (como em delegacias e serviços de assistência social) e (2) maior idade atual da criança aumentam a probabilidade de que ela venha a revelar o suposto abuso em juízo, tendo tais variáveis maior poder preditivo quanto à produção de um depoimento de qualidade do que a própria técnica de entrevista forense empregada (Azzopardi et al., 2019).

As técnicas projetivas temáticas também possibilitam a apreciação de habilidades cognitivas da criança, quando se deve considerar, em sua produção, "a amplitude do vocabulário, a riqueza do discurso, a diversidade de temas abordados, levando em conta a idade e o nível sociocultural do examinando" (Miguel et al., 2010, p 89). Já em termos de percepção adequada da realidade, pode-se comparar o tema das histórias do examinando com aqueles mais frequentemente evocados pelas crianças e adolescentes da amostra normativa dos testes (Miguel et al., 2010; Murray, 2005). Diferenças significativas entre elas sugerem que o sujeito pode ter percebido eventuais episódios não-abusivos como experiências de cunho sexual, o que tem sido observado em algumas falsas denúncias contra professores de esportes ou profissionais de saúde, os quais precisam tocar as crianças para exercer o seu trabalho (Rovinski \& Pelisoli, 2019).

Utilizando-se referencial adicional de análise dos dados do CAT-A (Xavier e Villemor-Amaral, 2013), pode-se obter uma estimativa aproximada do nível de desenvolvimento cognitivo do avaliando, segundo a teoria piagetiana. Em termos gerais, 
no período pré-operatório, haveria predominância de histórias fantasiosas, isto é, com interferência maior de elementos pessoais na apreensão da cena retratada, levando a uma interpretação e percepção mais distorcida da mesma. Além disso, pode ocorrer a justaposição de ideias e o sincretismo de pensamento que é uma junção de partes sem que esteja explicitada a ligação entre elas. O pensamento capta a informação, mas não assimila totalmente, apenas a justapõe a outra ideia, preponderante. Assim, a criança indica dificuldade em construir história a partir do estímulo apresentado, pois, ao fazê-lo, adiciona elementos externos, guiando-se mais por pensamentos e sentimentos individuais, levando a uma apreensão fantasiosa. Já no estágio das operações concretas, o relato da criança se atém ao estímulo, elaborando respostas precisas, convergentes com a cena retratada, uma vez que o pensamento se aplica predominantemente às informações reais e concretas disponíveis. Finalmente, no período das operações formais, espera-se que 0 indivíduo elabore histórias interpretativas, ultrapassando as informações concretas contidas no estímulo, revelando a capacidade para abstração, perceber e lidar com intenções, estabelecer relações lógicas entre os personagens, entre as causas e ações destes e suas consequências, entre os meios e os fins. (p. 40)

\section{QUANTIDADE DE INFORMAÇÃO NÃO-SUBSTANTIVA}

Um estudo quantitativo, utilizando 100 entrevistas forenses com crianças entre quatro e treze anos vítimas de suposta violência sexual, analisou a correlação entre a fase pré-substantiva e substantiva de seus depoimentos, isto é, aquela quando se demandam ao depoente informações não relacionadas ao suposto abuso (nome, idade, gostos, preferências, aspectos familiares etc.) e aquela em que se the solicitam, especificamente, detalhes do ocorrido (o que, onde e quando teria acontecido, e quem e como lhe teria feito). Percebeu-se que os depoentes que forneciam poucas informações na fase pré-substantiva tendiam à mesma conduta na fase substantiva, resistindo à produção de uma declaração com riquezas de detalhes, ou seja, um depoimento confiável do ponto de vista forense. Os autores, assim, recomendam a não proceder com a fase substantiva da entrevista caso a criança ou o adolescente promova poucas informações na pré-substantiva (Hershowitz, Orbach, Lamb, Sternberg, \& Horowitz, 2006).

Equiparando a avaliação prévia ao DE à fase pré-substantiva da entrevista forense - quando diversos assuntos são abordados mas não se adentra o conteúdo da violência em si -, sugere-se que o depoimento seja contraindicado quando a criança fornece pouca informação sobre si ou apresenta baixa produtividade nas provas projetivas. Isso pode ser avaliado não só pela entrevista psicológica, quando 
se constatam algumas crianças e adolescentes que mal respondem às perguntas realizadas sobre aspectos neutros de sua vida, como também pelo próprio material obtido por meio das provas temáticas. Histórias muito curtas, ou mesmo meras descrições dos estímulos objetivos das pranchas, acompanhadas ou não por atitude de apatia e desinteresse ante a situação avaliativa, apontam que o depoente não seria capaz de fornecer um relato forense rico em detalhes, a ponto de se tornar credível por parte dos operadores do Direito. Assim como Hershkowitz et al. (2006) sugerem, trata-se este de um indicativo para contraindicação do $D E$, considerando a possibilidade de desautorização do testemunho do depoente e logo, de danos psíquicos pela via intersubjetiva.

\section{RACIOCÍNIO MORAL E OPINIÃO DO DEPOENTE}

A Convenção Internacional Sobre os Direitos da Criança e do Adolescente (CDC), promulgada pelo Decreto no 99.710/1990 no Brasil, estabelece, em seu Art. 12, o direito de crianças e adolescentes em "expressar suas opiniões livremente sobre todos os assuntos relacionados com a criança". Isso implica que "se proporcionará à criança, em particular, a oportunidade de ser ouvida em todo processo judicial ou administrativo que afete a mesma" (Presidência da República, 1990b, p. 4).

Assim, cabe ao psicólogo judiciário explicar à criança e ao adolescente, na avaliação prévia ao $\mathrm{DE}$, a dinâmica do expediente criminal no qual eles constam como vítimas/testemunhas de um suposto delito, a função dos diferentes atores no processo penal e a demanda judicial para ouvi-los em juízo, possibilitando que o potencial depoente opine, de forma autônoma, sobre sua participação ou não no DE (Mello \& Faizibaioff, 2021). No caso dos adolescentes, trata-se de tarefa não tão complexa, devido ao maior grau de desenvolvimento cognitivo do qual gozam em relação às crianças menores, sobretudo pela capacidade de uso do raciocínio abstrato (Xavier \& Villemor-Amaral, 2013). Ademais, muitas vezes eles já assistiram a séries televisivas nas quais constam cenas de julgamentos criminais, tendo alguma representação prévia (Eloy, 2012) sobre a audiência para a qual são convidados a depor.

Com crianças pequenas, contudo, a captação de sua opinião é mais trabalhosa. Explicar-lhes os mesmos pontos acima elencados demanda maior flexibilidade instrumental e capacidade de comunicação metafórica por parte do avaliador. Primeiramente, então, estimar o grau de desenvolvimento de seu raciocínio moral ajuda nessa empreitada (Bataglia, Morais, \& Lepre, 2010), pois as concepções de certo/errado, justiça/injustiça e de infração/punição dos avaliandos facilitam a compreensão da dinâmica processual.

Muñoz et al. (2016) apontam que uma condição básica para averiguar se a criança tem condição de entender, razoavelmente, o papel de seu depoimento no processo penal é avaliar suas concepções sobre o bem versus o mal, o certo versus o errado e o justo versus injusto. Por meio de uma brincadeira, por exemplo, podese apresentar à criança uma situação concreta onde uma injustiça ocorre: seu professor a pune, sem provas, sob a acusação de furtar o estojo de um coleguinha 
na escola. Aí, pergunta-se à criança se ela acha aquilo justo ou injusto, e o porquê. Depois, questiona-se a criança sobre o que poderia ser feito para se demonstrar que não fora ela quem roubou o estojo, bem como para averiguar o verdadeiro culpado. Na experiência forense dos autores, observa-se que mesmo crianças mais novas têm demonstrado compreensão razoável dessa dinâmica, que constitui, grosso modo, a essência da produção probatória no processo penal. Os avaliandos costumam dar soluções adequadas para o impasse do roubo na escola, por exemplo, sugerindo que o professor verifique a mochila de cada aluno da sala, incluindo também a sua, de modo a encontrar o material furtado com outra criança. Então, pede-se à criança para imaginar o professor suspendendo a punição inicialmente a ela aplicada e transferindo-a ao verdadeiro culpado. Indagando-se o avaliando, finalmente, se esta segunda situação lhe parece justa ou injusta, ele tende a optar pela primeira opção, donde se observa um nível de raciocínio moral suficiente para compreender o contexto processual e emitir uma opinião autônoma sobre sua participação no DE.

Com essas jogadas metafóricas, aproximamo-nos das representações de justiça/injustiça da criança, equiparando a figura do professor à do juiz, a dos alunos acusados à do réu, a do aluno roubado à da vítima e a do processo de verificação do verdadeiro responsável à produção probatória por meio do $\mathrm{DE}$. Esse é um exemplo da

imposição de esforço ativo por parte de todo e qualquer adulto para que a criança ou adolescente tenham condições de exercer essa competência intelectual e jurídica que dita o art. 12 da Convenção sobre os Direitos da Criança. Se toda criança e adolescente têm garantido o direito à expressão de seus juízos e ao reconhecimento destes em todos os assuntos relacionados à vida da criança e do adolescente, incumbe, aos adultos, encontrar os critérios cognitivos e práticos que lhes permitam se posicionarem. (Melo, 2014, p. 102)

Se a opinião da criança e do adolescente quanto ao exercício de seu direito de depor é soberana (Presidência da República, 1990a, 1990b, 2017, 2018), cabe ao psicólogo judiciário, na avaliação, empregar os meios necessários para captá-la (Melo, 2014), defendendo-a intransigentemente ante os magistrados, promotores, advogados e os próprios responsáveis pela criança. Embora os juristas tenham se mostrado sensíveis em acatar os pareceres técnicos quanto à participação ou não das crianças e adolescentes no DE (Mello \& Faizibaioff, 2021), na experiência forense dos autores vê-se que alguns genitores nem sempre vão pelo mesmo caminho. Em determinadas situações, guiados pelo forte anseio de responsabilização penal do réu, eles insistem pelo $D E$, mesmo sendo informados de que o procedimento poderá trazer mais danos do que benefícios à integridade psíquica de sua prole.

E o contrário também acontece. Na experiência forense dos autores, um adolescente apresentou-se extremamente angustiado na avaliação. Os dados 
projetivos levantados pelo TAT sugeriram uma dinâmica defensiva precária naquele momento, a qual the poderia expor à ocorrência de dano intrapsíquico ante a invasão de altas cargas ansiogênicas quando do depoimento sobre a violência sofrida. Consultado, contudo, ele quis depor, mesmo the tendo sido explicado tais riscos pelo avaliador. Conversando com um jurista sobre a situação, este posicionou-se no sentido de que o parecer técnico deveria ser soberano ante a opinião do adolescente, isto é, dever-se-ia evitar-lhe qualquer risco, por mais que isso implicasse solapar sua opinião manifesta. Ainda assim, optou-se pelo caminho inverso, recomendando o DE ao magistrado, já que ficara claro o posicionamento do avaliando quanto ao exercício de um direito fundamental.

Esse exemplo atualiza, na avaliação prévia ao $D E$, uma tensão histórico-jurídica não resolvida mesmo com o advento de legislações especiais como o ECA (Presidência da República, 1990a) e o CDC (Presidência da República, 1990b). De um lado, concebem-se crianças e adolescentes como sujeitos autônomos, sendo sua opinião soberana à do adulto nos assuntos que lhes afetam; de outro, predomina a visão de objetos de proteção, quando se assume postura mais tutelar, isto é, a opinião do adulto sobre o que é melhor para a criança e o adolescente em detrimento das suas (Arantes, 2016).

Tal situação, conforme o exemplo acima, pode emergir quando da apreciação da opinião da criança quanto à participação no DE. Pois, ainda que a Lei $n^{\circ}$ 13.431/2017 e a própria CDC garantam que se trata de um direito ao depoimento, e não uma obrigação, o Código de Processo Penal brasileiro, em seu Art. 206, determina que "a testemunha não poderá eximir-se da obrigação de depor" (Presidência da República, 1941, p. 33). Observa-se, assim, um descompasso harmônico entre a legislação processual penal brasileira e aquela mais recente, referente aos direitos de crianças e adolescentes (Santos, 2014). Ainda que a qualidade processual de expedientes criminais envolvendo o DE esteja se aperfeiçoando por meio de aposta na interdisciplinaridade e produção de saber científico especializado (Mello \& Faizibaioff, 2021), cabe ao psicólogo ter consciência de tais tensões históricas e legislativas e como elas podem se atualizar no momento de captar a opinião da criança, devendo estar sempre preparado para complexas reflexões éticas em sua tomada de decisão (Rovinski \& Pelisoli, 2019).

\section{VINCULAÇÃO AO AVALIADOR-ENTREVISTADOR}

O mesmo psicólogo que realiza avaliação prévia atuará, no dia da audiência, como o entrevistador forense, caso não haja contraindicação à participação da criança/adolescente no DE. Assim, deve-se atentar às vicissitudes do binômio transferência-contratransferência (Ogden, 2013) quando do primeiro encontro do potencial depoente com o psicólogo-entrevistador, o que significa levar em conta, no raciocínio avaliativo, os próprios afetos, pensamentos e rêveries despertados no profissional quando da avaliação prévia ao DE (Villemor-Amaral \& Resende, 2018). Trata-se de aspectos relacionais que dão pistas sobre a qualidade da vinculação entre a crianças e o psicólogo, o que deve ser levado em conta na medida em que 
a disposição do interlocutor não só em escutar, como também em acolher um testemunho infantil impregnado de dor e sofrimento (Coimbra, 2014), diminui a possibilidade de que ela se sinta desautorizada em sua angústia (Osmo \& Kupermann, 2017).

Uma pesquisa empírica com grande número de depoimentos forenses observou que crianças e adolescentes cujos genitores eram divorciados tendiam a ter seus depoimentos judiciais sobre uma suposta violência sexual vivida menos dotados de credibilidade por parte de diferentes entrevistadores forenses devidamente treinados. Ao contrário da crença largamente difundida de que, necessariamente, isso dever-se-ia à maior probabilidade de falsas denúncias no contexto de divórcios litigiosos dos pais do infante, os autores sugeriram que tal resultado poderia ser reflexo de baixo suporte emocional que tais crianças recebiam de seus genitores, o qual lhes dificultava a produção de um relato com riqueza de detalhes e, logo, mais confiável do ponto de vista forense (Melkman et al., 2017).

Nesse sentido, observa-se o "reconhecimento da força disruptiva das ansiedades quando associadas a um objeto pouco ou nada receptivo às mesmas" (Salvitti, 2011, p. 131), ou seja, assim como na atividade na clínica, o entrevistador forense deve ter suficiente capacidade de continência (Ogden, 2013) para acolher quaisquer vivências angustiantes e disruptivas que emerjam em seu próprio psiquismo quando do testemunho da criança ou adolescente sobre a violência vivida. De forma que a qualidade do vínculo estabelecido entre o psicólogo e o potencial depoente, na avaliação prévia, é essencial para permitir à criança sentirse suficientemente amparada e autorizada, otimizando-se a confiabilidade de sua declaração forense obtida via DE.

Em termos avaliativos, destaca-se a utilidade da prancha 16 do TAT para apreciar a vinculação entre o avaliando e o psicólogo: nela, como solicitação latente, encontra-se a "maneira como o sujeito estrutura seus objetos internos e externos e organiza suas relações com eles" (Brelet-Foulard \& Chabert, 2008, p. 72), ou seja, ela pode dar pistas qualitativas, mesmo considerando o curto intervalo de tempo disponível para a avaliação prévia (Shine \& Lourenço, 2018; Grassano, 2012), da "relação transferencial na situação de teste" (Murray, 2005, p. 19). Avaliando uma adolescente supostamente violentada por um homem externo ao seu núcleo familiar, a figura masculina se lhe apresentou de forma altamente persecutória em todas as histórias construídas no TAT. Os personagens masculinos traíam, abandonavam, perseguiam, batiam, estupravam e matavam as do sexo feminino, ocupassem a posição que fosse: pai, irmão, filho ou avô. Quase todos os desfechos apresentaram-se de forma negativa e, na prancha 16, não parecia ser diferente: ela construiu uma história onde quatro irmãos, todos do sexo masculino, eram abandonados pelo pai. O mais velho, imbuído de anseios vingativos para com o genitor, assassinava os outros três e, ao final, suicidava-se. A história parecia finalizada quando ela, espontaneamente, acrescentou que o pai, extremamente culpado, voltou e enterrou os quatro filhos, e, após mais uma pausa carregada de intensa ansiedade depressiva, a avalianda finalmente pôde encerrar a narrativa: o 
pai mudava-se para outra cidade, conhecia uma nova mulher e tinha com ela um filho do sexo masculino. Indagada sobre o que aconteceria com essa criança no futuro, a avalianda disse que seria uma criança criada com todo o amor que os outros não tiveram. Trata-se de um desfecho positivo, criativo e adequado, o qual foi interpretado como fruto de um movimento reparatório em direção à figura masculina, até então imbuída de impiedosa destrutividade no psiquismo da avalianda. Em termos transferenciais-contratransferenciais, interpretou-se esse dado como um aspecto de vinculação positiva da adolescente ao avaliador, visto que este era do sexo masculino. O DE foi então indicado e por ele mesmo conduzido.

\section{ENTROSAMENTO DAS DIMENSÕES DO DANO PSÍQUICO}

Embora tratadas, com fins didáticos, separadamente neste artigo, a dimensão intrapsíquica e intersubjetiva do dano entrelaçam-se intimamente. A tentativa de atenuar excessos ansiogênicos pelo uso de mecanismos de defesas primitivos ou pouco sofisticados, embora seja uma tentativa desesperada de promover alívio rápido e radical à insuportável tensão intrapsíquica experimentada pelo depoente (Cintra \& Figueiredo, 2010), implica deterioração (Grassano, 2012) ou mesmo evacuação (Salvitti, 2011) de suas funções egóicas relacionadas com "os processos de pensamento, a linguagem, a percepção, a memória, a capacidade de julgar, a atenção" (p. 132). Também é atacada ou excindida, em tal configuração de coisas, a capacidade de diferenciação entre o interno e o externo (Piccolo, 2017), isto é, entre os produtos mentais gerados pelo processo da imaginação daqueles advindos da percepção (Pasquali, 2019). Trata-se, todas essas, de habilidades psicológicas imprescindíveis para a produção de um relato forense confiável (Köhnken et al., 2015).

Assim, ao dano intrapsíquico gerado pela baixa sofisticação das defesas da criança na lida contra altas cargas de ansiedade, associa-se o risco de perturbação de suas habilidades cognitivas caso ela se veja obrigada a lidar com um incremento abrupto de tensão mental, a qual é esperada em qualquer DE. Na dimensão intersubjetiva do dano, discutiu-se como o bom funcionamento da percepção, memória e raciocínio lógico, dentre outros processos cognitivos (Pasquali, 2019), é condição imprescindível para o depoente produzir uma declaração forense de qualidade, diminuindo as chances de desautorização traumática. Caso haja alterações significativas nessas competências, mesmo que temporariamente, tender-se-á à produção de uma declaração pouco confiável por parte da criança ou do adolescente, ameaçando-lhes de danos psíquicos pela via intersubjetiva, dado o risco de que o depoente veja sua palavra desmentida pelos atores do Poder Judiciário. É por isso que o psicólogo judiciário, na avaliação prévia ao $\mathrm{DE}$, deve buscar "o cuidado para garantir a integridade psíquica da criança e, ao mesmo tempo, o cuidado para garantir a validade e a confiabilidade de seu relato" (Benia, 2015 , p. 28). Trata-se, então, de avaliar o dano em sua natureza multidimensional. 


\section{LIMITAÇÕES}

Devido à natureza dinâmica e não cristalizada do "objeto escorregadio da Psicologia" (Pasquali, 2019, p. 6), o modelo de avaliação psicológica prévia ao DE neste artigo discutido não goza de total segurança em relação à predição de danos psíquicos. Mesmo com a aplicação de testes de personalidade e outros instrumentos projetivos junto às vítimas, "o fenômeno básico da comunicação são emoções pouco nítidas e obscuras: algo absolutamente difuso ao plano da consciência" (Trinca, 2017, p. 21). Infelizmente, não há garantias absolutas.

Por isso, deve-se ter extrema cautela na avaliação e condução do eventual DE. Caso o psicólogo judiciário observe, durante a execução deste, irrupções ansiogênicas potencialmente danosas que tenham escapado ao alcance preditivo da avaliação prévia, deve interrompê-lo imediatamente. A dimensão transferencialcontratransferencial (Ogden, 2013) é importante ferramenta para se manter atento a esse risco, além da necessidade de novos estudos sobre esta prática muito recente, visando à continuidade da discussão científica sobre modelos de avaliação psicológica que busquem indicar ou contraindicar a participação de crianças e adolescentes no DE.

\section{CONCLUSÃO}

A avaliação psicológica voltada para a predição de danos psíquicos associados ao depoimento especial (DE) de crianças e adolescentes vítimas e testemunhas de violência não se constitui, no curso do processo penal, como prova pericial. Antes, trata-se tão somente da averiguação da possibilidade de eventual produção de prova testemunhal, via DE. Caso não haja contraindicação técnica e ela concorde em participar do procedimento, a criança retorna ao Fórum, no dia da audiência em desfavor do réu, para exercer seu direito de tomar parte nos processos criminais cuja matéria lhe diz respeito, conforme as legislações vigentes.

A avaliação psicológica prévia à audiência é imprescindível para garantir a integridade psicológica das crianças e adolescentes vítimas ou testemunhas de violência, já que a mera aplicação de protocolos de entrevista forense para conduzir o DE não exclui, por si só, o risco de danos psíquicos ou revitimização desses sujeitos nos meandros do processo penal. $E$, na medida em que esse risco também encerra uma ameaça à própria confiabilidade da prova testemunhal dado o prejuízo às funções cognitivas do depoente em uma situação de excessiva atividade ansiogênica associada a um precário arsenal defensivo -, conclui-se que proteger a criança do processo penal é proteger o próprio processo penal.

\section{REFERÊNCIAS}

Alvarez, A. (1994). Abuso sexual de crianças: a necessidade de lembrar e a necessidade de esquecer. In A. Alvarez. Companhia Viva (pp. 161-172). Porto Alegre, RS: Artmed. 
Anaf, C., Menichetti, D., \& Evangelista, R. (2012). O ludodiagnóstico no contexto jurídico. In R. M. L. Affonso (Ed.). Ludodiagnóstico: Investigação clínica através do brinquedo (pp. 207-224). Porto Alegre, RS: Artmed.

Arantes, E. M. M. (2016). Duas décadas e meia de vigência da Convenção sobre os Direitos da Criança: algumas considerações. In E. P. Brandão (Ed.). Atualidades em Psicologia Jurídica (pp. 53-96). Rio de Janeiro, RJ: NAU.

Azzopardi, C., Eirich, R., Rash, C. L., MacDonald, S., \& Madigan, S. (2019). A meta-analysis of the prevalence of child sexual abuse disclosure in forensic settings. Child Abuse \& Neglect, 93, 291-304. https://doi.org/10.1016/j.chiabu.2018.11.02

Bataglia, P. U. R., Morais, A., \& Lepre, R. M. (2010). A teoria de Kohlberg sobre o desenvolvimento do raciocínio moral e os instrumentos de avaliação de juízo e competência moral em uso no Brasil. Estudos de Psicologia (Natal), 15(1), 25-32. http://dx.doi.org/10.1590/S1413294X2010000100004

Benia, L. R. (2015). A entrevista de crianças com suspeita de abuso sexual. Estudos de psicologia Campinas, 32(1), 27-35. https://doi.org/10.1590/0103-166X2015000100003

Bleger, J. (2015). A entrevista psicológica: seu emprego no diagnóstico e na intervenção. In: J. Bleger Temas de Psicologia: Entrevistas e grupos (4a ed.) (pp. 1-48). São Paulo, SP: Martins Fontes.

Brelet-Foulard, F., \& Chabert, C. (2008). Novo manual do TAT: Abordagem psicanalítica (2 ${ }^{\mathrm{a}}$ ed.). São Paulo, SP: Vetor.

Castanho, P. C. G. (2007). O momento da tarefa no grupo: aspectos psicanalíticos e psicossociais. Revista da SPAGESP, 8(2), 13-22. Recuperado de http://pepsic.bvsalud.org/pdf/rspagesp/v8n2/v8n2a03.pdf

Cintra, E. M. U., \& Figueiredo, L. C. (2010). Melanie Klein: Estilo e pensamento (2a ed.). São Paulo, SP: Escuta.

Coimbra, J. C. (2014). Depoimento especial de crianças: um lugar entre proteção e responsabilização? Psicologia: Ciência e Profissão, 34(2), 362-375. https://doi.org/10.1590/1982-3703000732013

Conselho Nacional de Saúde. (2016). Resolução n 510/2016 - Dispõe sobre a pesquisa em Ciências Humanas e Sociais. Brasil: Ministério da Saúde, Brasília, DF.

Eloy, C. B. (2012). A credibilidade do testemunho da criança vítima de abuso sexual no contexto judiciário. Psicologia: Ciência e Profissão, 32(1), 234-249. http://dx.doi.org/10.1590/S141498932012000100017

Faizibaioff, D. S.., \& Bandeira, M. L. (2017). Uso do D-E na composição do diagnóstico psicossocial no SUAS. In: L. S. L. P. C. Tardivo. (Ed.). O procedimento de Desenhos-Estórias na clínica e na pesquisa: 45 anos de percurso (pp. 1090-1102). São Paulo, SP: Instituto de Psicologia da USP. Recuperado de http://newpsi.bvs-psi.org.br/eventos/15_Apoiar.pdf

Grassano, E. (2012). Indicadores psicopatológicos em técnicas projetivas (R. Dantas, Trad.). São Paulo, SP: Martins Fontes.

Green, A. (2008). De locuras privadas. Buenos Aires, AR: Amorrotu.

Hershkowitz, I., Orbach, Y., Lamb, M. E., Sternberg, K. J., \& Horowitz, D. (2006). Dynamics of forensic interviews with suspected abuse victims who do not disclose abuse. Child Abuse \& Neglect, 30(7), 753-769. https://doi.org/10.1016/j.chiabu.2005.10.016

Intebi, I. V. (2008). Criterios de confirmación del diagnóstico de abuso sexual infantil. In I. V. Intebi. Valoración de sospechas de abuso sexual infantil (pp. 173-191). Cantabria, ES: Dirección General de Políticas Sociales.

Izquierdo, I. (2018). Memória (3 ${ }^{\mathrm{a}}$ ed.). Porto Alegre, RS: Artmed.

Köhnken, G., Manzanero, A. L., \& Scott, M. T. (2015). Análisis de la validez de las declaraciones: mitos y limitaciones. Anuario de Psicología Jurídica, 25(1), 13-19. https://doi.org/10.1016/j.apj.2015.01.004

Miguel, A.; Tardivo, L. C.; Silva, M. C. V. M., \& Tosi, S. M. V. (2010) CAT A: Teste de apercepção infantil: Figuras de animais: adaptado à população brasileira. São Paulo, SP: Vetor.

Melkman, E.P., Hershkowitz, I., \& Zur, R. (2017). Credibility assessment in child sexual abuse investigations: a descriptive analysis. Child Abuse \& Neglect, 67, 76-85. ttps://doi.org/10.1016/j.chiabu.2017.01.027

Mello, A. C. C. \& Faizibaioff, D. S. (2021). Depoimento especial de crianças e adolescentes: Experiências e reflexões do SANCTVS. In C. J. L. Pereira \& E. Z. M. Silva. (Eds.). Psicologia judiciária e segurança social: Relações entre o Direito e a Psicologia (pp. 17-32). São Paulo, SP: Quartier Latin do Brasil. 
Melo, E. R. (2014). Crianças e adolescentes vítimas de abuso sexual: a emergência de sua subjetividade jurídica no embate entre os modelos jurídicos de intervenção e seus direitos. Uma análise crítica sob o crivo histórico-comparativo à luz do debate em torno do depoimento especial. In B. R. Santos, I. B. Gonçalves, M. G. O. M. Vasconcelos, P. B. Barbieri, \& V. N. Viana. (Eds.). Escuta de crianças e adolescentes em situação de violência sexual: Aspectos teóricos e metodológicos (pp. 91-112). Brasília, DF: Editora da Universidade Católica de Brasília.

Muñoz, J. M., González-Guerrero, L., Sotoca, A., Teral, O., González, J. L., \& Manzanero, A. L. (2016). La entrevista forense: obtención del indicio cognitivo en menores presuntas víctimas de abuso sexual infantil. Papeles del Psicólogo, 37(3), 205-216. Recuperado de http://www.papelesdelpsicologo.es/pdf/2777.pdf

Murray, H. A. (2005). T.A.T. Teste de Apercepção Temática. (3ª ed.). São Paulo, SP: Casa do Psicólogo.

Ogden, T. H. (2013). Reverie e interpretação: Captando algo humano. São Paulo, SP: Escuta.

Osmo, A., \& Kupermann, D. (2017). Trauma e testemunho: uma leitura de Maryan S. Maryan inspirada em Sándor Ferenczi. Psicologia Clínica, 29(3), 471-493. Recuperado de http://pepsic.bvsalud.org/pdf/pc/v29n3/07.pdf

O'Donohue, W., Cummings, C., \& Willis, B. (2018). The frequency of false allegations of child sexual abuse: a critical review. Journal of Child Sex Abuse, 27(5), 459-475. https://doi.org/10.1080/10538712.2018.1477224

Pasquali, L. (2019). Os processos cognitivos. São Paulo, SP: Vetor.

Piccolo, E. G. (2017). Defesas nos testes gráficos. In M. L. S. Ocampo, M. E. G. Arzeno, \& E. G. Piccolo (Eds.). O processo psicodiagnóstico e as técnicas projetivas (11ª ed.) (pp. 255-380). São Paulo, SP: Martins Fontes.

Pinto, E. R. (2014). Conceitos fundamentais dos métodos projetivos. Ágora: Estudos em Teoria Psicanalítica, 17(1), 135-153. http://dx.doi.org/10.1590/S1516-14982014000100009

Presidência da República. Casa Civil. Subchefia para Assuntos Jurídicos. (1941). Decreto-Lei $n^{\circ} 3.689$ de 3 de outubro de 1941. Código de Processo Penal. Brasília, DF. Recuperado de http://www.planalto.gov.br/ccivil_03/decreto-lei/del3689.htm

Presidência da República. Casa Civil. Subchefia para Assuntos Jurídicos. (1990a). Lei nº 8.069, de 13 de julho de 1990. Dispõe sobre o Estatuto da Criança e do Adolescente. Brasília, DF Recuperado de http://www.planalto.gov.br/ccivil_03/leis//8069.htm

Presidência da República. Casa Civil. Subchefia para Assuntos Jurídicos. (1990b). Decreto $n^{\circ} 99.710$, de 21 de novembro de 1990. Promulga a Convenção sobre os Direitos da Criança. Brasília, DF. Recuperado de http://www.planalto.gov.br/ccivil_03/decreto/1990-1994/D99710.htm

Presidência da República. Secretaria-Geral. Subchefia para Assuntos Jurídicos. (2017). Lei $n^{\circ} 13.431$, de 4 de abril de 2017. Estabelece o sistema de garantia de direitos da criança e do adolescente vítima ou testemunha de violência e altera a Lei n 8.069, de 12 de julho de 1990 (Estatuto da Criança e do Adolescente). Brasília, DF. Recuperado de http://www.planalto.gov.br/ccivil_03/_ato2015-2018/2017/lei/l13431.htm

Presidência da República. Secretaria-Geral. Subchefia para Assuntos Jurídicos. (2018). Decreto $n^{\circ}$ 9.603, de 10 de dezembro de 2018. Regulamenta a Lei $n^{\circ} 13.431$, de 4 de abril de 2017, que estabelece o sistema de garantia de direitos da criança e do adolescente vítima ou testemunha de violência. Brasília, DF. Recuperado de http://www.planalto.gov.br/ccivil_03/_Ato20152018/2018/Decreto/D9603.htm

Rosenblum, R. (2002) ¿Se puede morir de decir? Sarah Kofman, Primo Levi. Psicoanálisis APdeBA 24(1), 147-176. Recuperado de https://www.psicoanalisisapdeba.org/wpcontent/uploads/2019/02/rosenblum.pdf

Rovinski, S. L. R. (2008). A avaliação do dano psíquico em mulheres vítimas de violência. In S. Shine (Ed.). Avaliação psicológica e lei: Adoção, vitimização, separação conjugal, dano psíquico e outros temas ( $2^{\mathrm{a}}$ ed.) (pp. 175-190). São Paulo, SP: Pearson.

Rovinski, S. L. R., \& C.L. Pelisoli, C. L. (2019). Violência sexual contra crianças e adolescentes: Testemunho e avaliação psicológica. São Paulo, SP: Vetor.

Salvitti, A. (2011). A aurora da simbolização: contribuições iniciais de Bion a uma teoria da observação e do pensamento primitivo. Revista Brasileira de Psicanálise, 45(2), 127-138. Recuperado de http://pepsic.bvsalud.org/pdf/rbp/v45n2/v45n2a21.pdf

Seligmann-Silva, M. (2008). Narrar o trauma: a questão dos testemunhos de catástrofes históricas. Psicologia Clínica [online], 20(1), 65-82. https://doi.org/10.1590/S0103-56652008000100005

Santos, B. R. (2014). Por uma escuta da criança e do adolescente social e culturalmente contextualizada: concepções de infância e de adolescência, universalidade de direitos e 
respeito às diversidades. In B. R. Santos; I. B. Gonçalves, M. G. O. M. Vasconcelos; P. B. Barbieri, \& V. N. Viana. Escuta de crianças e adolescentes em situação de violência sexual: aspectos teóricos e metodológicos (pp. 27-42). Brasília, DF: Editora da Universidade Católica de Brasília.

Santos, A. R., \& Coimbra, J. C. (2017). O depoimento judicial de crianças e adolescentes entre apoio e inquirição. Psicologia: Ciência e Profissão, 37(3), 595-607. https://doi.org/10.1590/19823703004032016

Schaeffer, P., Leventhal, J. M., \& Asnes, A .G. (2011). Children's disclosures of sexual abuse: learning from direct inquiry. Child Abuse and Neglect, 35(5), 343-352. https://doi.org/10.1016/j.chiabu.2011.01.014

Shine, S., \& Lourenço, A. S. (2018). Problemáticas a enfrentar na escrita do laudo psicológico. In A. S. Lourenço, M. C. M. Ortiz, \& S. Shine (Eds.). Produção de documentos escritos em Psicologia: Prática e reflexões teórico-críticas (pp. 139-154). São Paulo, SP: Vetor.

Subijana, I. G., \& Echeburúa, E. (2018). Los menores víctimas de abuso sexual en el proceso judicial: el control de la victimización secundaria y las garantias jurídicas de los acusados. Anuario de Psicología Jurídica, 28(1), 22-27. https://doi.org/10.5093/apj2018a1

Tardivo, L. S. L. P. C. (2016). A violência doméstica em crianças e adolescentes: expressão e compreensão das consequências com o uso de métodos projetivos. In E.T. K. Okino, P. F. Castro, F. L. Osório, S. R. Pasian, S. A. Scortegagna, L. M. Cardoso, F. R. Freitas, \& A. E. Villemor-Amaral (Eds.). Métodos projetivos e suas demandas na Psicologia contemporânea (pp. 13-25). Florianópolis, SC: ASBRo.

Tardivo, L. S. L. P. C (2020). Procedimento de Desenhos-Estórias: diferentes formas de interpretação. In W. Trinca (Org.). Formas lúdicas de investigação em Psicologia: Procedimento de DesenhosEstórias e Procedimento de Desenhos de Família com Estórias (pp. 67-85). São Paulo, SP: Vetor.

Thouvenin, C. (1997). A palavra de criança: do íntimo ao social. In M. Gabel (Ed.). Crianças vítimas de abuso sexual (pp. 91-102). São Paulo, SP: Summus.

Torres, M. S. (2014). Adolescência e abuso sexual intrafamiliar: Avaliação dos impactos psicológicos e reajustes identitários-identificatórios com métodos projetivos. (Dissertação de Mestrado). Universidade de Brasília, Brasília.

Trinca, W. (2017). Palestra de abertura comemoração: 45 anos do D-E. In: L. S. L. P. C. Tardivo. (Ed.). O procedimento de Desenhos-Estórias na clínica e na pesquisa: 45 anos de percurso (pp. 21-24). São Paulo, SP: Instituto de Psicologia da USP. Recuperado de http://newpsi.bvspsi.org.br/eventos/15_Apoiar.pdf

Trinca, W. (2020). Formas lúdicas de investigação em Psicologia: Procedimento de Desenhos-Estórias e Procedimento de Desenhos de Família com Estórias. São Paulo, SP: Vetor.

Villemor-Amaral, A. E., \& Resende, A. C. (2018). Novo modelo de avaliação psicológica no Brasil. Psicologia: Ciência e Profissão, 38(spe), 122-132. https://doi.org/10.1590/19823703000208680

Volbert, R., \& Steller, M. (2014). Is this testimony truthful, fabricated, or based on false memory? Credibility assessment 25 years after Steller and Köhnken (1989). European Psychologist, 19(3), 207-220. https://doi.org/10.1027/1016-9040/a000200

Xavier, M. F., \& Villemor-Amaral, A E. (2013). Avaliação do funcionamento cognitivo por meio do CATA: evidências de validade. Psicologia: Reflexão e Crítica, 26(1), 38-46. https://doi.org/10.1590/S0102-79722013000100005

\section{CONFLITOS DE INTERESSES}

Não há conflitos de interesses.

\section{SOBRE OS AUTORES}

Danilo Salles Faizibaioff é mestre e doutorando em Psicologia Clínica pelo Instituto de Psicologia da USP (IPUSP), psicólogo judiciário do Tribunal de Justiça do Estado de São Paulo (TJSP) e docente de Psicologia na Fundação Santo André (FSA-SP).

E-mail: danilo.faizibaioff@usp.br

(2) https://orcid.org/0000-0002-6242-9967 
Leila Salomão de La Plata Cury Tardivo é doutora em Psicologia Clínica, Livre Docente em Psicopatologia e Professora Associada do Departamento de Psicologia Clínica do Instituto de Psicologia da USP. É responsável por pesquisas com apoio FAPESP e CNPq e coautora de manuais de testes psicológicos aprovados pelo Conselho Federal de Psicologia (CFP).

E-mail: tardivo@usp.br

(2) https://orcid.org/0000-0002-8391-0610 